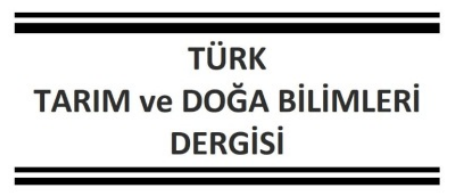

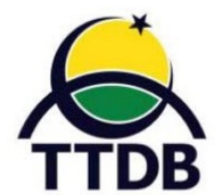

www.dergipark.gov.tr/turkjans

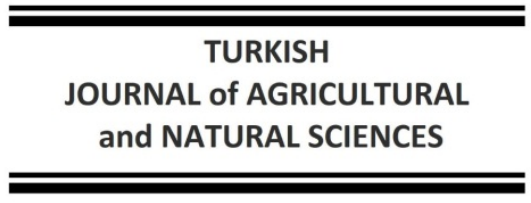

ORNAL Of AGRICULTURAL

\title{
Araştırma Makalesi \\ Tuz Stresinin Tek Yıllık Çim (Lolium multiflorum L.)'de Çimlenme ve Fide Gelişim Özelliklerine Etkisi
}

\author{
Ayşe Özge ŞiMŞEK SOYSAL*1, Gürkan DEMIRKOL ${ }^{1}$, Özlem ÖNAL AŞCl ${ }^{1}$, Yeliz KAŞKO ARICI ${ }^{2}$, \\ Zeki ACAR $^{3}$, Nuri YILMAZ ${ }^{1}$ \\ ${ }^{1}$ Ordu Üniversitesi Ziraat Fakültesi Tarla Bitkileri Bölümü, Ordu \\ ${ }^{2}$ Ordu Üniversitesi Tıp Fakültesi Biyoistatistik ve Tıbbi Bilişim Anabilim Dalı, Ordu \\ ${ }^{3}$ Ondokuz Mayıs Üniversitesi Ziraat Fakültesi Tarla Bitkileri Bölümü, Samsun \\ *Sorumlu Yazar: ayseozgesimsek@odu.edu.tr
}

Geliş Tarihi: 28.08.2020 Düzeltme Geliş Tarihi: 09.03.2021 Kabul Tarihi: 06.04.2021

\section{Öz}

Günümüzde tarım, artan nüfus için bugünden daha fazla gıda üretmek gibi birçok zorlukla karşı karşıyadır ancak gıda talebine paralel olarak ürün verimi artmamaktadır. Düşük verim birçok abiyotik stres faktörüyle ilişkilidir. Tuzluluk, verim ve kaliteyi düşüren büyük bir abiyotik stres faktörüdür. Bu çalışma, Lolium multiflorum'un tuzluluğa toleransını saptamak amacıyla kurulmuştur. Materyal olarak Lolium multiflorum'un Caramba çeşidi kullanılmıştır. Çalışmada 11 farklı $\mathrm{NaCl}$ dozu (0, 20, 40, 60, 80, 100, 120, 140, 160, 180, 200 $\mathrm{mM}$ ) uygulanmıştır. Çalışmada, çimlenme oranı,ortalama çimlenme süresi, radikula ve plumula uzunluğu, radikula ve plumula yaş ağırlığı ile radikula ve plumula kuru ağırlığı hesaplanmıştır. Araştırmada, tuz stresi tüm parametrelerde istatistiki olarak anlamlı bir farka sebep olmuştur. Tuz, dozlara bağlı olarak parametreleri pozitif ve negatif etkilemiştir. 20 ve $40 \mathrm{mM}$ tuz dozlarında pozitif etki görülürken, $140 \mathrm{mM}$ tuz dozu ve sonrasında genellikle negatif etki meydana gelmiştir.

Anahtar kelimeler: Fizyolojik stres, stres fizyolojisi, yem bitkisi

\section{The Effect of Salt Stress on the Germination and Seedling Growth Parameters in Italian Ryegrass (Lolium multiflorum L.)}

\begin{abstract}
Today, the agriculture is facing a lot of difficulties such as producing more food than today for the increasing population but the yielding of crops is not increasing in parallel with the food demand. This study was conducted in order to determine the salinity tolerance of Lolium multiflorum. A Lolium multiflorum cultivar Caramba was used as a material in the study. The salinity stress applications were made in petri dishes with 11 $\mathrm{NaCl}$ concentrations $(0,20,40,60,80,100,120,140,160,180,200 \mathrm{mM})$. In the study, the values of germination rate, mean germination time (day), the length of radicula and plumula, radicula fresh and dry weight, plumula fresh and dry weight were determined. In the study, salt stress caused significant differences in all parameters. $\mathrm{NaCl}$ affected the parameters positively or negatively depending on application doses in the study. While the positive effects of salt application occurred in 20 and $40 \mathrm{mM}$, the negative effects of salt application usually occurred in $140 \mathrm{mM}$.
\end{abstract}

Key words: Physiological tolerance, stress physiology, forage crop.

\section{Giriş}

Ülkemizde kaliteli kaba yem açı̆̆ını kapatmak için yem bitkileri ekim alanını genişletmemiz ve verimliliği de artırmamız gerekmektedir. $\mathrm{Bu}$ nedenle mevcut yem bitkilerinin yanı sıra yeni tür ve çeşitlerin ekilmesi gerekmektedir. Tek yıllık yem bitkileri ara ürün olarak kullanıma uygun olduklarından, ülkemizde 
daha çok tercih edilmektedirler. Bu noktadan hareketle tek yıllık çim, gerek yalın gerekse baklagillerle karışık ekilerek kışlık ara ürün olarak değerlendirilmektedir.

Tuzluluk yarı kurak ve kurak bölgelerde daha çok sorun olmakla birlikte (Ekmekçi ve ark., 2005), yanlış sulama uygulamalarında, drenaj problemi yaşanan alanlarda (Kanber ve ark., 2005) ve deniz tuzluluğundan etkilenen kıyı ovalarında ortaya çıkmaktadır (Cemek ve ark., 2006). Bu nedenle tuzluluk ülkemizde yaşanan en önemli abiyotik stress faktörlerinden biridir. Türkiye'de yaklaşık 12 bin ha alanda tuzluluk problemi yaşanmaktadır (Çulha ve Çakırlar, 2011). Dahası küresel iklim değişikliğine bağlı olarak ülkemizde tuzluluk probleminin artacağı düşünülmektedir (Türkeş ve ark., 2000).

Doğada çok farklı tuzlar bulunmakla birlikte en yaygın bulunan tuz $\mathrm{NaCl}$ 'dir (Kuşvuran, 2010). $\mathrm{NaCl}$ osmotik stres ve/veya toksik etki oluşturarak bitki yaşamını olumsuz etkilemektedir (Çulha ve Çakırlar, 2011). Bitkinin yaşam periyodu içerisinde tuz stresine karşı en hassas olduğu dönem çimlenme dönemi olarak rapor edilmiştir (Ahmad ve ark., 2013). Yapılan birçok araştırma sonucunda farklı bitki türlerinde tuz dozuna bağlı olarak çimlenmenin önemli ölçüde azaldığı (Güngör ve ark., 2017) ve hatta engellendiği belirlenmiştir (Önal Aşcl, 2011; Önal Aşcl ve Üney, 2016; Özkorkmaz ve Yılmaz, 2017).

Tuzlu toprakların ıslahı ekonomik olmayan bir süreç olduğu için, bu alanlarda tuzluluğa dayanıklı bitkilerin yetiştirilmesi daha uygun olmaktadır (Turhan ve Şeniz, 2010). Bu nedenle son yıllarda bitki tür ve çeşitlerinin tuzluluğa dayanımı üzerinde çalışmalar yoğunlaşmıştır.

$\mathrm{Bu}$ çalışma Lolium multiflorum'a ait Caramba çeşidinde farklı tuz dozlarının çimlenme ve fide gelişimine etkisini belirlemek amacıyla yürütülmüştür.

\section{Materyal ve Metot}

$\mathrm{Bu}$ çalışma farklı tuz konsantrasyonlarının Lolium multiflorium'da çimlenme ve fide gelişimi üzerine etkisini belirlemek amacıyla Ordu Üniversitesi Ziraat Fakültesi Tarla Bitkileri Bölümü Laboratuvarında 2018 yılında yürütülmüştür. Çalışmada Lolium multiflorium'un Caramba çeşidine ait tohumlar kullanılmıştır. Tohumlar sterilize edilmek için \%2'lik sodyum hipokloritte 1 dakika çalkalanmış ardından $3 \mathrm{kez}$ saf sudan geçirilmiştir. Çalışmada petri kaplarına 11 tuz dozu $(0,20,40,60,80,100,120,140,160,180,200$ $\mathrm{mM}$ ) uygulanmıştır. Deneme tesadüf parselleri deneme desenine göre 10 tekrarlı olarak kurulmuştur. Denemede her tekrar için 50 adet tohum kullanılmıştır. Tohumlar, petride filtre kağıtları arasına yerleştirilmiştir. Her petriye ayrı ayrı dozlarda $10 \mathrm{ml} \mathrm{NaCl}$ solüsyonu eklenmiştir. Petri kapları, iklimlendirme dolabında tamamen karanlık ortamda $20 \pm 1{ }^{\circ} \mathrm{C}^{\prime}$ de 7 gün boyunca çimlenmeye bırakılmıştır. Deneme süresince tohumlar her gün kontrol edilmiş ve $3 \mathrm{~mm}$ radikula uzunluğuna sahip tohumlar çimlenmiş olarak kabul edilmiştir. Çalışmada, çimlenme oranı (\%), ortalama çimlenme süresi (gün), radikula ve plumula uzunlukları $(\mathrm{cm})$, yaş radikula ve plumula ağırıkları (g) ile kuru radikula ve plumula ağırlıkları (g) hesaplanmıştır. Çalışmada uzunluk ve ağırlık ölçümleri 10 örnek üzerinden yapılmıştır.

Çimlenme Oranı (\%)=(Çimlenen tohum sayısı/toplam tohum sayısı) $\times 100$

Ortalama Çimlenme süresi $=\Sigma(\mathrm{fx}) / \Sigma \mathrm{f}$ (Matthews ve Khajeh-Hosseini, 2007).

( $\Sigma$ : toplam, $\mathrm{f}$ : sayım günündeki çimlenen tohum sayısı, $\mathrm{x}$ : sayım yapılan gün sayısı).

Verilerin normal dağılım kontrolü Shapiro-Wilk testi ile grup varyanslarının homojenlik kontrolü Levene testi ile yapılmıştır. Araştırmada elde edilen verilere Tesadüf Parselleri Deneme Desenine göre varyans analizi yapılmış ve ortalamalar arasındaki farklılık Tukey testi ile belirlenmiştir. Hesaplamalarda ve yorumlamalarda $\alpha=\% 5$ dikkate alınmıştır. Tüm hesaplamalar Minitab v18 istatistik paket programı ile yapılmıştır.

\section{Bulgular ve Tartışma}

Yapılan varyans analizi sonucunda, çimlenme oranı ve ortalama çimlenme süresi bakımından tuz dozları arasında istatistiki olarak farklılık olduğu $(p<0.001)$ belirlenmiştir. Tuz stresi kontrole göre çimlenmeyi çoğunlukla azaltıcı etki yapmış, ancak tuz dozundaki artış her zaman çimlenme oranını doğrusal olarak azaltmamıştır (Çizelge 1). Dolayısıyla, 160 ve 200 mM tuz dozları haricindeki tüm tuz dozları istatistiki olarak kontrolle aynı grupta yer almışlardır. Nitekim çalışmada belirlenen çimlenme oranı \% 91.4 ile 97.8 arasında değişim göstermiş ve uygulanan en yüksek tuz dozunda dahi oldukça yüksek (\% 91.4) çimlenme gerçekleşmiştir (Çizelge 1).

Kuşvuran ve ark. (2015) Lolium perenne ile yaptıkları çalışmada 150 ve 200 mM NaCl'nin çimlenmeyi olumsuz etkilediğini bildirmişlerdir. Her ne kadar iki araştırmada kullanılan türler farklı olsa da akraba türler olması nedeniyle sonuçlar birbirine benzer bulunmuştur. Çimlenme ortamına $20 \mathrm{mM} \mathrm{NaCl}$ ilavesi çimlenme süresini kısaltmasına rağmen, $40 \mathrm{mM}$ ve üzeri tuz dozları çimlenme süresini uzatmıştır (Çizelge 2). Kontrolle karşılaştırıldığında istatistiki olarak ilk önemli etki $60 \mathrm{mM}$ dozunda ortaya çıkmış, çimlenme süresini en fazla uzatan uygulama ise $200 \mathrm{mM}$ dozu olmuştur. Tuzluluğun çimlenmeyi olumsuz etkileme 
sebeplerinden birisi osmotik stres oluşturmasıdır (Doğan ve Budaklı Çarpıcı, 2016). Bilindiği üzere tohumun su alması tohum ile içinde bulunduğu ortamın osmotik potansiyeline bağlıdır. Ayrıca tohumun çimlenmeye başlaması için her türün kendine has kritik nem seviyesine ulaşılması gerekmektedir. Araştırmamızda kullanılan tohum materyali, buğdaygil bitkisi olması nedeniyle karyopsisin iç kavuzlarla çevrilmesi ile oluşmuş yapıdadır. Tohumu saran bu yapılardan özellikle iç kavuzlar muhtemelen tohumun su alma gücünü arttırıcı etki yapmakla birlikte tohumun kritik nem seviyesine ulaşması için ihtiyacı olan su miktarını da artırmaktadır. Bu nedenlerle 200 mM'a kadar uygulanan dozlarda tuzluluğun çimlenme oranına olumsuz etkisi önemsiz olurken, çimlenme süresine olan olumsuz etkisi çok daha düşük dozlarda gerçekleşmiştir. Nitekim Nizam (2011),'ın elde ettiği sonuçlar bulgularımızı desteklemektedir. Araştırıcı, çok yıllık çim tohumlarının yüksek tuz dozunda (24 dS/m) dahi ilk 3 saat içinde kontrol grubundaki tohumlar ile aynı oranda su aldığını, ancak süre ilerledikçe yüksek tuz dozlarında tohumların su alım oranlarının azaldığını belirlemiştir.

Çizelge 1. Farklı tuz dozlarının çimlenme oranına (\%) etkisi için tanıtıcı istatistik değerleri ve karşılaştırma sonuçları $(n=10)$.

\begin{tabular}{lllll}
\hline Doz $(\mathrm{mM})$ & Ortalama & Std. Hata & En düşük & En yüksek \\
\hline Kontrol & $97.60 \mathrm{~A}$ & 0.653 & 94.00 & 100.00 \\
20 & $97.40 \mathrm{~A}$ & 0.600 & 94.00 & 100.00 \\
40 & $96.60 \mathrm{~A}$ & 0.792 & 92.00 & 100.00 \\
60 & $97.20 \mathrm{~A}$ & 0.611 & 94.00 & 100.00 \\
80 & $95.40 \mathrm{AB}$ & 0.670 & 92.00 & 98.00 \\
100 & $94.40 \mathrm{ABC}$ & 0.653 & 92.00 & 98.00 \\
120 & $97.80 \mathrm{~A}$ & 0.629 & 96.00 & 100.00 \\
140 & $97.20 \mathrm{~A}$ & 0.680 & 94.00 & 100.00 \\
160 & $92.40 \mathrm{BC}$ & 0.653 & 90.00 & 96.00 \\
180 & $95.20 \mathrm{AB}$ & 0.904 & 90.00 & 100.00 \\
200 & $91.40 \mathrm{C}$ & 1.267 & 86.00 & 98.00 \\
\hline
\end{tabular}

P-değeri $0.000^{* * *}(\mathrm{~F}=8.226)$

*istatistik olarak önemlidir $(\mathrm{p}<0.001)$; Ortak büyük harfi olmayan dozlar arasındaki fark istatistiksel olarak önemlidir $(p<0.05)$.

Çizelge 2. Farklı tuz dozlarının ortalama çimlenme süresine (gün) etkisi için tanıtıcı istatistik değerleri ve karşılaştırma sonuçları $(n=10)$.

\begin{tabular}{lllll}
\hline Doz $(\mathrm{mM})$ & Ortalama & Std. Hata & En düşük & En yüksek \\
\hline Kontrol & $2.23 \mathrm{FG}$ & 0.102 & 1.73 & 2.66 \\
20 & $1.99 \mathrm{G}$ & 0.102 & 1.40 & 2.39 \\
40 & $2.57 \mathrm{EF}$ & 0.062 & 2.24 & 2.86 \\
60 & $2.73 \mathrm{DE}$ & 0.058 & 2.40 & 3.06 \\
80 & $3.17 \mathrm{C}$ & 0.069 & 2.78 & 3.43 \\
100 & $3.01 \mathrm{CD}$ & 0.107 & 2.47 & 3.39 \\
120 & $3.18 \mathrm{C}$ & 0.065 & 2.85 & 3.62 \\
140 & $3.07 \mathrm{CD}$ & 0.037 & 2.88 & 3.24 \\
160 & $3.37 \mathrm{BC}$ & 0.057 & 3.13 & 3.64 \\
180 & $3.64 \mathrm{~B}$ & 0.078 & 3.30 & 4.16 \\
200 & $4.08 \mathrm{~A}$ & 0.102 & 3.57 & 4.51 \\
\hline
\end{tabular}

P-değeri $0.000^{* * *}(\mathrm{~F}=57.441)$

* istatistik olarak önemlidir ( $p<0.001)$; Ortak büyük harfi olmayan dozlar arasındaki fark istatistiksel olarak önemlidir $(p<0.05)$.

Araştırmada tuz dozlarının fide gelişimine etkisini belirlemek için plumula uzunluğu, plumula yaş ve kuru ağırlığı, radikula uzunluğu, radikula yaş ve kuru ağırlığı incelenmiştir. Çizelge 3-8'de görüldüğü üzere farklı tuz konsantrasyonları Lolium multiflorum fidelerinde radikula ve plumula gelişimini istatistiki olarak önemli $(p<0.001)$ düzeyde etkilemiştir.
Düşük tuz uygulamaları (20 ve $40 \mathrm{mM} \mathrm{NaCl}$ ) radikula ve plumula gelişimini olumlu etkilerken, 60 $\mathrm{mM}$ ve üzeri tuz dozlarında ise radikula ve plumula gelişiminin olumsuz etkilenmeye başladığı belirlenmiştir. Bilindiği üzere $\mathrm{Na}+\mathrm{ve} \mathrm{Cl}$ - iyonları bitkiler için besin elementidir. Düşük dozlarda radikula ve plumula gelişiminin teşvik edilmesi muhtemelen besin etkisinden kaynaklanmıştır. 
Çizelge 3. Farklı tuz dozlarının radikula uzunluğuna $(\mathrm{cm})$ etkisi için tanıtıcı istatistik değerleri ve karşılaştırma sonuçları $(n=10)$.

\begin{tabular}{lllll}
\hline Doz $(\mathrm{mM})$ & Ortalama & Std. Hata & En düşük & En yüksek \\
\hline Kontrol & $4.10 \mathrm{AB}$ & 0.193 & 2.94 & 5.10 \\
20 & $4.60 \mathrm{~A}$ & 0.247 & 3.44 & 5.62 \\
40 & $5.04 \mathrm{~A}$ & 0.159 & 4.22 & 5.80 \\
60 & $3.40 \mathrm{~B}$ & 0.363 & 2.02 & 4.98 \\
80 & $3.52 \mathrm{~B}$ & 0.283 & 1.92 & 4.54 \\
100 & $3.57 \mathrm{~B}$ & 0.300 & 2.06 & 4.94 \\
120 & $3.15 \mathrm{~B}$ & 0.175 & 2.52 & 3.96 \\
140 & $1.36 \mathrm{C}$ & 0.116 & 0.87 & 2.04 \\
160 & $1.04 \mathrm{C}$ & 0.061 & 0.78 & 1.45 \\
180 & $0.97 \mathrm{C}$ & 0.031 & 0.84 & 1.14 \\
200 & $0.45 \mathrm{D}$ & 0.019 & 0.36 & 0.58 \\
\hline
\end{tabular}

P-değeri $0.000 * * *(\mathrm{~F}=59.216)$

* istatistik olarak önemlidir ( $p<0.001)$; Ortak büyük harfi olmayan dozlar arasındaki fark istatistiksel olarak önemlidir $(p<0.05)$.

Çizelge 4. Farklı tuz dozlarının plumula uzunluğuna $(\mathrm{cm})$ etkisi için tanıtıcı istatistik değerleri ve karşılaştırma sonuçları $(n=10)$

\begin{tabular}{lllll}
\hline Doz $(\mathrm{mM})$ & Ortalama & Std. Hata & En düşük & En yüksek \\
\hline Kontrol & $5.68 \mathrm{ABC}$ & 0.270 & 4.12 & 7.22 \\
20 & $6.52 \mathrm{AB}$ & 0.393 & 4.55 & 8.22 \\
40 & $6.84 \mathrm{~A}$ & 0.234 & 5.88 & 8.44 \\
60 & $4.78 \mathrm{C}$ & 0.487 & 3.01 & 7.11 \\
80 & $5.01 \mathrm{C}$ & 0.373 & 3.00 & 6.36 \\
100 & $5.16 \mathrm{BC}$ & 0.418 & 3.21 & 7.14 \\
120 & $4.49 \mathrm{C}$ & 0.302 & 3.25 & 6.32 \\
140 & $1.87 \mathrm{D}$ & 0.125 & 1.15 & 2.45 \\
160 & $1.32 \mathrm{D}$ & 0.101 & 0.98 & 2.15 \\
180 & $1.44 \mathrm{D}$ & 0.060 & 1.20 & 1.78 \\
200 & $0.66 \mathrm{E}$ & 0.030 & 0.55 & 0.85 \\
\hline P-değeri & $0.000^{* * *}(\mathrm{~F}=57.342)$ & & \\
\hline * istatistik olarak önemlidir ( $\mathrm{p}<0.001) ;$ Ortak büyük harfi olmayan dozlar arasındaki fark istatistiksel olarak \\
önemlidir (p<0.05).
\end{tabular}

Çizelge 5. Farklı tuz dozlarının radikula yaş ağırlığına (g) etkisi için tanıtıcı istatistik değerleri ve karşılaştırma sonuçları $(n=10)$

\begin{tabular}{lllll}
\hline Doz $(\mathrm{mM})$ & Ortalama & Std. Hata & En düşük & En yüksek \\
\hline Kontrol & $0.046 \mathrm{ABC}$ & 0.023 & 0.034 & 0.059 \\
20 & $0.051 \mathrm{AB}$ & 0.027 & 0.039 & 0.061 \\
40 & $0.057 \mathrm{~A}$ & 0.018 & 0.049 & 0.067 \\
60 & $0.038 \mathrm{C}$ & 0.039 & 0.023 & 0.056 \\
80 & $0.040 \mathrm{BC}$ & 0.034 & 0.022 & 0.051 \\
100 & $0.041 \mathrm{BC}$ & 0.032 & 0.023 & 0.051 \\
120 & $0.035 \mathrm{C}$ & 0.023 & 0.028 & 0.047 \\
140 & $0.016 \mathrm{D}$ & 0.017 & 0.009 & 0.028 \\
160 & $0.012 \mathrm{D}$ & 0.006 & 0.009 & 0.014 \\
180 & $0.011 \mathrm{D}$ & 0.006 & 0.008 & 0.013 \\
200 & $0.006 \mathrm{E}$ & 0.003 & 0.004 & 0.007 \\
\hline P-değeri & $0.000 * * *(\mathrm{~F}=55.764)$ & & \\
\hline
\end{tabular}

* istatistik olarak önemlidir $(\mathrm{p}<0.001)$; Ortak büyük harfi olmayan dozlar arasındaki fark istatistiksel olarak önemlidir ( $p<0.05)$. 
Çalışmamızla benzer olarak, Kuşvuran ve ark. (2008), 50 mM NaCl uygulamasının bazı Lolium perenne çeşitlerinde radikula yaş ağırlığını artırdığını belirlemişlerdir. Nizam (2011) ise $\mathrm{NaCl}$ dozlarının Lolium perenne de hem radikula hem de plumula gelişimini düşük tuz dozunda önce arttırdığını sonra ise artan tuz dozu ile azalttığını bildirmiştir. Artan dozlarda ise osmotik etkisi ve/veya toksik etkisiyle (Çulha ve Çakırlar, 2011) bitki gelişimini olumsuz etkilemiştir. Kuraklığa maruz kalmış bitkilerde absisik asit sentezi artar, absisik asit sürgün büyümesini engeller (Taiz ve Zeiger, 2002). Yine hücreler turgor durumunu sağlayamadıklarında hücre büyümesi ve buna bağlı olarak hücre bölünmesi gerçekleşemez.

Çizelge 6. Farklı tuz dozlarının plumula yaş ağırlığına (g) etkisi için tanıtıcı istatistik değerleri ve karşılaştırma sonuçları $(n=10)$

\begin{tabular}{|c|c|c|c|c|}
\hline $\operatorname{Doz}(\mathrm{mM})$ & Ortalama & Std. Hata & En düşük & En yüksek \\
\hline Kontrol & $0.179 \mathrm{AB}$ & 0.080 & 0.135 & 0.221 \\
\hline 20 & $0.207 \mathrm{~A}$ & 0.131 & 0.143 & 0.259 \\
\hline 40 & $0.219 \mathrm{~A}$ & 0.062 & 0.184 & 0.255 \\
\hline 60 & 0.154 B & 0.154 & 0.095 & 0.242 \\
\hline 80 & 0.155 B & 0.117 & 0.091 & 0.199 \\
\hline 100 & $0.163 \mathrm{~B}$ & 0.104 & 0.114 & 0.220 \\
\hline 120 & $0.140 \mathrm{~B}$ & 0.096 & 0.103 & 0.198 \\
\hline 140 & $0.059 \mathrm{C}$ & 0.041 & 0.036 & 0.075 \\
\hline 160 & $0.041 \mathrm{C}$ & 0.034 & 0.031 & 0.069 \\
\hline 180 & $0.044 \mathrm{C}$ & 0.024 & 0.030 & 0.055 \\
\hline 200 & $0.011 \mathrm{D}$ & 0.009 & 0.006 & 0.015 \\
\hline P-değeri & $0.000 * * *$ & & & \\
\hline
\end{tabular}

* istatistik olarak önemlidir ( $p<0.001)$; Ortak büyük harfi olmayan dozlar arasındaki fark istatistiksel olarak önemlidir ( $\mathrm{p}<0.05)$.

Çizelge 7. Farklı tuz dozlarının radikula kuru ağırlığına (g) etkisi için tanıtıcı istatistik değerleri ve karşılaştırma sonuçları $(n=10)$

\begin{tabular}{lllll}
\hline Doz $(\mathrm{mM})$ & Ortalama & Std. Hata & En düşük & En yüksek \\
\hline Kontrol & $0.012 \mathrm{ABC}$ & 0.009 & 0.006 & 0.016 \\
20 & $0.012 \mathrm{AB}$ & 0.007 & 0.009 & 0.015 \\
40 & $0.013 \mathrm{~A}$ & 0.004 & 0.011 & 0.015 \\
60 & $0.009 \mathrm{CD}$ & 0.010 & 0.005 & 0.013 \\
80 & $0.009 \mathrm{CD}$ & 0.007 & 0.005 & 0.012 \\
100 & $0.009 \mathrm{BCD}$ & 0.008 & 0.005 & 0.013 \\
120 & $0.008 \mathrm{D}$ & 0.005 & 0.007 & 0.010 \\
140 & $0.004 \mathrm{E}$ & 0.003 & 0.002 & 0.005 \\
160 & $0.003 \mathrm{E}$ & 0.002 & 0.002 & 0.004 \\
180 & $0.003 \mathrm{E}$ & 0.001 & 0.002 & 0.003 \\
200 & $0.002 \mathrm{E}$ & 0.001 & 0.001 & 0.002 \\
\hline P-değeri & $0.000^{* * *}(\mathrm{~F}=51.516)$ & & \\
\hline
\end{tabular}

* istatistik olarak önemlidir ( $p<0.001$ ); Ortak büyük harfi olmayan dozlar arasındaki fark istatistiksel olarak önemlidir $(p<0.05)$.

Stres şartlarında bitkilerde absisik asit, etilen ve brassinostreroid sentezlendiği ve söz konusu bileşiklerin radikula gelişimini değiştirdiği, genellikle düşük tuz dozlarının radikula uzamasını teşvik ettiği, yüksek dozların ise radikula gelişimini azalttığı bildirilmiştir (Julkowska ve ark., 2014). Radikula bölgesindeki tuz, osmotik stres ve toksik iyon etkisi ile radikula meristem dokusunda hücre genişlemesini ve hücre üretimini engelleyerek radikula uzamasını azaltır (Rewald ve ark., 2013). $\mathrm{Bu}$ nedenlerle artan tuz dozlarında olumsuzluklar yaşanmaya başlanmıştır. Kontrol ile karşılaştırıldığında, radikula kuru ağırlığı hariç, incelenen diğer plumula ve radikulaya ait özelliklerde, tuz dozunun ilk önemli olumsuz etkisi 140 mM dozunda gerçekleşmiştir. Ayrıca 140 ile 180 mM dozları da dahil bu aralıktaki uygulamalar istatistiki olarak birbirinden farksız bulunmuşlardır. Söz konusu özelliklerde tuz stresinin en büyük olumsuz etkisi $200 \mathrm{mM}$ dozunda gerçekleşmiştir. Radikula kuru ağırlığında ise $120 \mathrm{mM}$ tuz dozunda kontrole göre önemli derecede azalma yaşanmış, artan tuz dozlarının (140-200 mM) radikula kuru ağırlığına olumsuz etkisi daha da büyük olmuştur. 
Çizelge 8. Farklı tuz dozlarının plumula kuru ağırlığına (g) etkisi için tanıtıcı istatistik değerleri ve karşılaştırma sonuçları $(n=10)$.

\begin{tabular}{lllll}
\hline Doz $(\mathrm{mM})$ & Ortalama & Std. Hata & En düsük & En yüksek \\
\hline Kontrol & $0.029 \mathrm{ABC}$ & 0.015 & 0.020 & 0.035 \\
20 & $0.034 \mathrm{AB}$ & 0.022 & 0.024 & 0.043 \\
40 & $0.036 \mathrm{~A}$ & 0.012 & 0.031 & 0.044 \\
60 & $0.025 \mathrm{C}$ & 0.025 & 0.016 & 0.037 \\
80 & $0.026 \mathrm{C}$ & 0.019 & 0.016 & 0.033 \\
100 & $0.027 \mathrm{BC}$ & 0.022 & 0.017 & 0.037 \\
120 & $0.023 \mathrm{C}$ & 0.016 & 0.017 & 0.033 \\
140 & $0.010 \mathrm{D}$ & 0.007 & 0.006 & 0.013 \\
160 & $0.007 \mathrm{D}$ & 0.005 & 0.005 & 0.011 \\
180 & $0.008 \mathrm{D}$ & 0.003 & 0.006 & 0.009 \\
200 & $0.003 \mathrm{E}$ & 0.002 & 0.003 & 0.004 \\
\hline P-değeri & $0.000^{* * *}(\mathrm{~F}=55.630)$ & & \\
\hline
\end{tabular}

* istatistik olarak önemlidir ( $p<0.001)$; Ortak büyük harfi olmayan dozlar arasındaki fark istatistiksel olarak önemlidir ( $p<0.05)$.

\section{Sonuç ve öneriler}

Sonuç olarak; Araştırmada incelenen tüm parametreler birlikte değerlendirildiğinde, tek yıllık çim (Lolium multiflorum) Caramba çeşidinin çimlenme ve fide gelişimi bakımından $120 \mathrm{mM}$ $\mathrm{NaCl}$ dozuna kadar olan tuz uygulamalarını tolere edebildiği sonucuna varılmıştır.

Çıkar Çatışması Beyanı: Makale yazarları aralarında herhangi bir çıkar çatışması olmadı̆̆ını beyan ederler.

\section{Araştırmacıların Katkı Oranı Beyan Özeti:} Yazarlar makaleye eşit oranda katkı sağlamış olduklarını beyan ederler.

\section{Kaynaklar}

Ahmad, P., Azooz, M.M. ve Prasad, M.N.V., 2013. Salt Stress in Plants. Heidelberg: Springer, 495s.

Cemek, B., Güler, M. ve Arslan, H., 2006. Bafra ovası sağ sahil sulama alanındaki tuzluluk dağılımının coğrafi bilgi sistemleri (CBS) kullanılarak belirlenmesi. Atatürk Üniversitesi Ziraat Fakültesi Dergisi, 37(1): 63-72.

Çulha, Ş. ve Çakırlar, H., 2011. Tuzluluğun bitkiler üzerine etkileri ve tuz tolerans mekanizmaları. Afyon Kocatepe Üniversitesi Fen Bilimleri Dergisi, 11: 11- 34.

Doğan R. ve Çarpıcı, E.B., 2016. Farklı tuz konsantrasyonlarının bazı tritikale hatlarının çimlenmesi üzerine etkileri. Kahramanmaraş Sütçü İmam Üniversitesi Doğa Bilimleri Dergisi, 19(2): 130-135.

Ekmekçi, E., Apan, M. Ve Kara, T., 2005. Tuzluluğun bitki gelişimine etkisi. Ondokuz Mayıs Üniversitesi Ziraat Fakültesi Dergisi, 20(3): 118- 125
Güngör, H., Dokuyucu, T., Dumlupinar, Z. ve Akkaya, A., 2017. Determination of relationships between grain yield and some agronomic traits by correlation and path analysis in oat (Avena spp.). Journal of Tekirdag Agricultural Faculty, 14(1): 61-68.

Julkowska, M.M., Hoefsloot, H.C.J., Mol, S., Feron, R., Boer, G-J de, Haring, M.A. ve Testerink, C., 2014. Capturing Arabidopsis root architecture dynamics with ROOT-FIT reveals diversity in responses to salinity. Plant Physiology, 114.

Kanber, R., Çullu, M.A., Kendirli, B., Antepli, S. ve Yılmaz, N., 2005 Sulama, drenaj ve tuzluluk. 3-7 Ocak, Ziraat Mühendisleri Odası 6. Teknik Kongresi Bildiri Kitabı.

Kuşvuran, A., Nazlı, R.I. ve Kuşvuran, Ş., 2015. The effects of salinity on seed germination in perennial ryegrass (Lolium perenne L.) varieties. Türk Tarım ve Doğa Bilimleri Dergisi, 2(1): 78-84.

Kuşvuran, Ş., 2010 Kavunlarda kuraklık ve tuzluluğa toleransın fizyolojik mekanizmaları arasındaki bağlantılar. Çukurova Üniversitesi Fen Bilimleri Enstitüsü (Basılmamış), Doktora Tezi. Adana, $356 \mathrm{~s}$.

Kuşvuran, Ş., Yaşar, F., Abak, K., ve Ellialtıoğlu, Ş., 2008. Tuz stresi altında yetiştirilen tuza tolerant ve duyarlı Cucumis sp.'nin bazı genotiplerinde lipid peroksidasyonu, klorofil ve iyon miktarlarında meydana gelen değişimler. Yüzüncü Yıl Üniversitesi Tarım Bilimleri Dergisi, 18(1): 13-20.

Matthews, S. ve Khajeh-Hosseini M., 2007. Length of the lag period of germination and metabolic repair explain vigour differences in seed lots of maize (Zea mays). Seed Science and Technology, 35: 200-212.

Nizam, I., 2011. Effects of salinity stress on water uptake, germination and early seedling growth of perennial ryegrass. African 
Journal of Biotechnology, 10(51): 1041810424.

Önal Aşcı, Ö., 2011. Salt tolerance in red clover (Trifolium pratense L.) seedlings. African Journal of Biotechnology, 10(44): 87748781.

Önal Aşcl, Ö. ve Üney, H., 2016. Farklı tuz yoğunluklarının macar fiğinde (Vicia pannonica Crantz) çimlenme ve bitki gelișimine etkisi. Akademik Ziraat Dergisi, 5(1): 29-34.

Özkorkmaz, F. ve Yılmaz, N., 2017. Farklı tuz konsantrasyonlarının fasulye (Phaseolus vulgaris L.) ve börülcede (Vigna unguiculata L.) çimlenme üzerine etkilerinin belirlenmesi. Ordu Üniversitesi Bilim ve Teknoloji Dergisi, 7(2): 196-200.
Rewald, B., Shelef, O., Ephrath, J.E., Rachmilevitch, S., 2013. Adaptive plasticity of salt-stressed root systems. In Ecophysiology and responses of plants under salt stress ( $\mathrm{pp}$. 169-201). Springer, New York, NY.

Taiz, L. ve Zeiger, E., 2002. Plant Physiology, Sinauer Associates, 623s.

Turhan, A. ve Șeniz, V., 2010. Salt tolerance of some tomato genotypes grown in Turkey. Journal of Food, Agriculture \& Environment, 8(3/4 part 1): 332-339.

Türkeş, M., Sümer, U.M., Çetiner, G., 2000. Küresel İklim Değişikliği ve Olası Etkileri. Çevre Bakanlığı, Birleşmiş Milletler İklim Değişikliği Çerçeve Sözleşmesi Seminer Notları, 7-24. 